\title{
A new radiodont (stem Euarthropoda) frontal appendage with a mosaic of characters from the Cambrian (Series 2 Stage 3) Chengjiang biota
}

Jin Guo', Stephen Pates ${ }^{2.3^{3}}$, Peiyun Cong ${ }^{4,5,6^{6}}$, Allison C. Daley ${ }^{3}$, Gregory D. Edgecombe ${ }^{5,6}$, Taimin Chen ${ }^{1}$ and Xianguang $\mathrm{Hou}^{4,6}$

'Management Committee of the Chengjiang Fossil Site World Heritage, Chengjiang 652599, China; email:16172066@qq.com, 309205403@qq.com

2Department of Zoology, University of Oxford, Oxford OX1 3PS, UK; email:

stephen.pates@zoo.ox.ac.uk

${ }^{3}$ Institute of Earth Sciences, University of Lausanne, Lausanne CH-1015, Switzerland; email:

allison.daley@unil.ch

${ }^{4}$ Yunnan Key Laboratory for Palaeobiology, Yunnan University, Kunming 650091, China; email: cong@ynu.edu.cn,xghou@ynu.edu.cn

'Department of Earth Sciences, The Natural History Museum, Cromwell Road, London SW7 5BD,

UK; email: p.cong@nhm.ac.uk, g.edgecombe@nhm.ac.uk

${ }^{\circ}$ MEC International Joint Laboratory for Palaeobiology and Palaeoenvironment, Yunnan

University, Kunming 650091 China.

* Corresponding author

\begin{abstract}
:
The classification of Radiodonta is primarily based on the morphology of their frontal appendages, a main feeding structure of this iconic group of mostly Cambrian stem-group euarthropods. However, recent progress in the description and revision of radiodont taxa, particularly drawing on their frontal appendages, has exposed morphological variation that challenges reliable identification of higherlevel groupings. Here we describe a new taxon of Radiodonta, Laminacaris chimera gen. et sp. nov., from the Cambrian Series 2, Stage 3, Chengjiang biota of China, based on unique frontal appendage morphology. Laminacaris is distinctive for its combination of characters shared by hurdiids and other early Cambrian radiodont families. Elongated, possibly unpaired endites on two proximal podomeres that bear small distally-directed auxiliary spines oriented perpendicular to the long axis of the endite, are comparable with the elongated endites and their auxiliary spines of all known Cambrian members of Hurdiidae. In contrast, endites on more distal podomeres are similar to some species of Anomalocaris, and the dorsal spines at the distal end resemble those of Amplectobelua. The mosaic characters in the frontal appendage of Laminacaris chimera may capture morphology close to the divergence between the major radiodont groups.
\end{abstract}

Key words: Radiodonta, Hurdiidae, frontal appendage, Laminacaris chimera gen. et sp. nov., Chengjiang Biota

\section{Introduction:}

Radiodonta Collins 1996, putative stem-group Euarthropoda, is represented worldwide by over 25 species reported from Cambrian Series 2 to at least the Ordovician and likely the Early Devonian. As the earliest active large predators in the animal fossil record, most radiodonts used paired frontal appendages to capture and subdue prey. These frontal appendages are segmented structures bearing numerous spines, attached to the ventral surface of the head, anterolateral to the mouth and associated oral structures. The frontal appendages show considerable morphological variation across taxa, ranging from the triangular, simple-spined Caryosyntrips Daley \& Budd, 2010, through to an elongated appendage with paired spines of the iconic taxon Anomalocaris Whiteaves, 1892, to the complex and setigerous, giant Aegirocassis Van Roy et al., 2015. Frontal appendages are important structures for understanding radiodont taxonomy, particularly because many species are known only from isolated frontal appendages, such as Amplectobelua stephenensis Daley \& Budd, 2010, Anomalocaris pennsylvanica Resser, 1929, Caryosyntrips serratus Daley \& Budd, 2010, C. camurus Pates \& Daley, 2017, C. durus Pates \& Daley, 2017, Peytoia infercambriensis (Lendzion, 1975), 
Stanleycaris hirpex Pates et al., 2018a, and Tamisiocaris borealis Daley \& Peel, 2010. Owing to this, phylogenetic analyses of radiodont interrelationships have focused primarily on frontal appendage characters (Vinther et al. 2014), with four putative clades recovered, namely Anomalocarididae Raymond, 1935, Amplectobeluidae Vinther et al., 2014, Hurdiidae Vinther et al., 2014, and 'Cetiocaridae', each of which has a distinctive frontal appendage morphology (e.g. Cong et al. 2018). However, these four families have only been diagnosed using phylogenetic definitions (Vinther et al. 2014; Van Roy et al. 2015) rather than character-based diagnoses, although efforts have been made to evaluate the potential diagnostic characters of some families. Hurdiidae is the most diverse family, including at least the genera Hurdia Walcott, 1912, Peytoia Walcott, 1911, Stanleycaris Pates et al., 2018a, Aegirocassis Van Roy et al., 2015, and probably Schinderhannes Kühl et al., 2009, as recovered by cladistic analyses (Vinther et al. 2014; Cong et al. 2014; Van Roy et al. 2015). Numerous frontal appendage characteristics are shared among these taxa, especially among the Cambrian members. The endites on several of the proximal articulated podomeres are unpaired and elongated, bearing auxiliary spines that are perpendicular to the endite and distallydirected. These endites are rigid and closely packed, forming a pattern of overlapping auxiliary spines to hold prey, or to filter food particles. Head carapaces and mouthparts are also distinctive in members of Hurdiidae, as exemplified by the enlarged tripartite frontal carapaces and the tetra-radial oral cone with a central opening, which in Hurdia has extra rows of spinose plates (Daley \& Bergström, 2012; Daley et al. 2009, 2013a, Van Roy et al. 2015). The Family Amplectobeluidae has also been given a character-based diagnosis (Cong et al. 2018), its members characterized by three pairs of gnathobaselike structures with nearly identical morphology, and frontal appendages with three shaft podomeres and enlarged endites on podomeres 4 and (Cong et al. 2017, 2018).

Of the family-level groups sensu Vinther et al. (2014), more difficulty surrounds Anomalocarididae and 'Cetiocaridae'. Erected in 1935, Anomalocarididae Raymond, 1935 was firstly defined as a euarthropod group by bearing a Tuzoia-carapace and a trunk that is 'elongate, large with appendages on all segments except the last one' (Raymond 1935), with the trunk later being reinterpreted as a frontal appendage (Briggs 1979). After the body puzzle of the type species of the nominate genus Anomalocaris was resolved (Whittington \& Briggs, 1985), the diagnosis of this family was revised by Hou et al. (1995), and new taxa have sporadically been assigned to it (e.g. Anomalocaris briggsi, A. kunmingensis). However, recent phylogenetic analysis revealed that even the type genus Anomalocaris is non-monophyletic (Vinther et al. 2014; Cong et al. 2014; Van Roy et al. 2015). These results indicate that morphological re-appraisal at generic and specific levels are required before diagnostic characters of Anomalcoarididae can be summarized. 'Cetiocaridae' is not ICZN compliant (Van Roy et al. 2015) and this family should be named using the genus on which its phylogenetic definition was based, Tamisiocaris.

The early Cambrian Chengiiang biota from Yunnan, China is well-known for a diverse assemblage of radiodonts, with 5 genera and 7 species documented so far. Members of both Anomalocarididae (Anomalocaris saron Hou et al., 1995) and Amplectobeluidae (Amplectobelua symbrachiata Hou et al., 1995, Ramskoeldia consimilis Cong et al., 2018 and $R$. platyacantha Cong et al., 2018) are well represented, while several other species cannot be assigned with confidence to any existing families, such as Cucumericrus decoratus Hou et al. 1995, Lyrarapax unguispinus Cong et al., 2014 and L. trilobus Cong et al., 2016 (Cong et al. 2018). Several types of sclerotized carapaces from the Chengiiang biota have been described as remains of hurdiids, some of which were named as a new genus Tauricornicaris Zeng et al., 2018 (Zeng et al. 2018). However, articulated specimens of the same sclerites indicate that Tauricornicaris is not radiodont, but rather the tergites of a more crownward euarthropod (Cong et al. 2018). Here we describe a new taxon from the Chengiiang biota showing a unique mix of frontal appendage characters, of which the elongated endites bearing auxiliary spines confined to one side are shared with Hurdiidae. However, other features, namely the shape of the podomeres, morphology and size of ventral endites and dorsal spines in the distal articulated region, suggest an alternative affinity with Anomalocarididae and Amplectobeluidae.

\section{Materials and methods}

Specimens were collected from the lower part of the mudstones of the Yu'anshan Member, Chiungchussu Formation in eastern Yunnan Province, China, which falls within the Eoredilichia- 
Wutingaspis biozone, in the Chinese local Nangaoan Stage (equivalent to the global Cambrian Series 2, Stage 3). RCCBYU 10251 and YKLP 13338 were collected from the Mafang section in the Haikou area, Kunming, and CJHMD 00003 was collected from the Fengkoushao section, Chengjiang. Detailed stratigraphic information and localities can be found in Hou et al. (2017). When necessary, the specimens were prepared with a steel needle under a Nikon SMZ 1000 stereomicroscope. Images were taken with Canon EOS 5D SR camera mounted with Canon MP-E $65 \mathrm{~mm}$ (1-5X) or Canon EF $100 \mathrm{~mm}$ macro lenses in cross-polarized light, and were adjusted for colour and brightness/contrast with Adobe Photoshop CC 2014.2.2. Interpretative drawings were produced with Adobe Photoshop CC 2014.2.2 by tracing the images while viewing the specimens. Figures were also assembled in Adobe Photoshop CC 2014.2.2.

Terminology. The descriptive terminology of the frontal appendage mainly follows that of Daley \& Edgecombe (2014), with the term 'shaft' (Hou et al. 1995) being employed to describe the proximal podomere(s) of the frontal appendage (see also Cong et al. 2017, 2018) and 'ventral endite' used in place of 'ventral spine' as it describes any inward projection (including spines) that are presumably used in feeding. The 'distal articulated region' consists of those podomeres distal to the shaft region, characterised by well-defined podomere boundaries and usually a consistent pattern of arrangement of the ventral endites (see also Cong et al. 2017, 2018).

Institutional abbreviations. YKLP, Yunnan Key Laboratory for Palaeobiology; RCCBYU, Research Center of Chengiiang Biota, Yunnan University, previous name of YKLP. CJHMD, Chengjiang Fossil Museum of the Management Committee of the Chengjiang Fossil Site World Heritage.

Abbreviations. As, auxiliary spines; ds, dorsal spine; en, ventral endite; pd, podomere; ts, terminal spine.

\title{
Systematic Palaeontology
}

\author{
Superphylum PANARTHROPODA Nielsen, 19951904 \\ Order RADIODONTA Collins, 1996
}

LSID. urn:lsid:zoobank.org.

Genus LAMINACARIS nov. gen.

Derivation of name: from the Latin 'lamina' meaning thin blade, and 'caris' meaning crab, a suffix commonly used for marine arthropods. Gender feminine.

Type species: Laminacaris chimera $\mathrm{n}$. sp.

Diagnosis: Radiodont with frontal appendages consisting of 15 podomeres, including two podomeres (podomeres 1 and 2) in the 'shaft' and 13 (podomeres 3-15) in the distal articulated region; each podomere bears a single ventral endite that attaches to midpoint of ventral surface in all podomeres except podomere 2 , where the ventral endite attaches to distal ventral surface of podomere, and podomere 1, which does not bear an endite; endites on podomeres 2 and 3 larger and stouter than others; podomere 3 with multiple distally-pointing auxiliary spines which increase in length towards tip of ventral endite; endites on podomeres 4-13 alternating short/long on odd/even numbered podomeres, bearing one proximal and up to three distally pointing auxiliary spines; five large dorsal spines on podomeres 11-15; reduced terminal spine on podomere 15 .

Laminacaris chimera $\mathrm{n}$. sp.

(Figs 1, 2A-E)

v. 2004 Anomalocaris aff. saron; Hou et al., p. 95, fig. 15.2b

LSID. urn:lsid:zoobank.org. 
Derivation of name: chimera, from the creature in Greek mythology composed of parts of more than one animal. This reflects the similarities of different parts of the frontal appendage of this new species with a number of radiodont genera.

Holotype: RCCBYU 10251, part and counterpart, preserving an isolated frontal appendage with complete shaft but poorly preserved distal end.

Paratypes: YKLP 13338, preserving most of an isolated frontal appendage with a complete distal end; CJHMD 00003, a nearly complete isolated frontal appendage.

Occurrence: Yu'anshan Member, Chiungchussu Formation in eastern Yunnan Province, China, Chinese local Nangaoan stage (equivalent to Cambrian Series 2, Stage 3).

Diagnosis: As for genus.

Description: This taxon is known from three nearly-complete or complete frontal appendages, all of which are relatively large in size compared to other Chengjiang radiodonts (Figs 1, 2A-D). The length of the three (measuring the outer edge of podomeres exclusive of the shaft ones) ranges from $11 \mathrm{~cm}$ (holotype RCCBYU 10251) to over $28 \mathrm{~cm}$ (paratype YKLP 13338, only measured from preserved podomeres 4-15). In general, the frontal appendage is stout, dividing into a shaft and a distal articulated region. The shaft is incomplete in CJHMD 00003 and not preserved in YKLP 13338, but it is clear in the holotype RCCBYU 10251, bearing two podomeres with the boundary between them difficult to discern (Fig. 1A, B, E, F). In the shaft, a ventral endite arises from the distal ventral surface of podomere 2 ; it is elongate and simple, bearing one distally-directed small auxiliary spine (Figs 1A, F; 2A, E). In both RCCBYU 10251 and CJHMD 00003, the shaft attaches to the distal articulated region without forming an angle at the outer edge of the joint (Figs 1A, B, E, F; 2A-D).

The distal articulated region bears 13 podomeres (podomeres 3 to 15) that are separated by distinct triangular flexible membranous areas (Figs 1A, B, E, F; 2A-D). The podomeres are generally rectangular in shape, with their height greater than their length. Each articulated podomere, except the most distal one (podomere 15), has a ventral endite that attaches to the midpoint of their ventral surface. The endites alternate long/short on odd/even numbered podomeres. The ventral endite on podomere 3 is distinctly larger and stouter than others, and is closely associated with the endite of shaft podomere 2, the two together forming a distinctive branching near the base of the frontal appendage (Figs 1A, B, E, F; 2A-D). The ventral endite on podomere 3 bears five large distallydirected auxiliary spines that increase in size towards the tip of the endite. Between each of these is a smaller distally-pointing auxiliary spine (arrows in Figs 2C, E). Podomere 3 also bears a proximallypointing auxiliary spine, approximately $2 / 3$ of the way down the endite (Figs $1 \mathrm{H} ; 2 \mathrm{E}$ ). The length of the auxiliary spines never exceeds the width of the endite, as is also seen in the auxiliary spines on all other endites. The endites on podomeres 4-14 are shorter than the height of the podomeres to which they attach and are bilaterally asymmetrical. They curve slightly towards the distal end of the frontal appendages, with up to three auxiliary spines pointing distally and only one proximally. When preserved, the proximal pointing auxiliary spine attaches to the endite near its tip, at the same point as the most tipwards auxiliary spine on the other side (Figs 1A-C, E-G; 2A-D). The ventral endite on podomere 7 is nearly the same size as the endite of podomere 5, or slightly larger (Fig. 2A-D). In YKLP 13338, the ventral endite on podomere 7 appears larger than that of podomere 5 (Fig. 1D, G), though this could be taphonomic as the tip of the ventral endite on podomere 5 does not appear to be complete. Each of podomeres 11-15 bears one large dorsal spine that arises from the distal-most corner of the podomere and curves forward following the outline of the appendage, with each having a length that exceeds their associated podomere (Fig. 1C, D, G). A tiny, simple terminal spine is present on podomere 15 (Fig. 1C, D, G).

Remarks: These specimens are undoubtedly radiodont frontal appendages, owing to the presence of such characteristics as triangular arthrodial membrane between sclerotised podomeres, the tapering outline of the appendage, differentiated shaft and distal articulated regions, ventral endites, and dorsal and terminal spines. The elongate ventral endite on P3 of Laminacaris resembles in detailed morphology the ventral endites characteristic of the hurdiids Hurdia, Stanleycaris and some species of 
Peytoia. Other aspects of the appendage bear similarities to members of the families

Anomalocarididae and Amplectobeluidae (see Table 1).

The elongated endites on podomeres 2 (shaft) and 3 (distal articulated region) of Laminacaris chimera have a straight blade-like morphology that is comparable to the ventral endites of hurdiids. The podomere 3 endite in particular, with its multiple short robust auxiliary spines that point distally, alternate in size, and are arranged perpendicular to the endite, resemble the ventral endites of Hurdia appendages (Daley et al. 2009, 2013a). In Laminacaris chimera, the increasing size of the auxiliary spines towards the tip of the ventral endite, with small auxiliary spines between the larger auxiliary spines, is also present on the ventral endites of Hurdia appendages, such as ROM 60048 (Daley et al. 2013a, fig 12 C, D) and ROM 60020 (Daley et al. 2013a, fig 12 E). Hurdia might also have a shaft with two podomeres (Fig. 2H, pd1, pd2), with the distal one bearing an elongated, probably spineless, endite (Fig. 2H, arrow), resembling the arrangement of podomeres 1 and 2 in the shaft of Laminacaris (Fig. 1B, F). However, all known genera of Hurdiidae bear five proximal podomeres with unpaired elongated endites and at least four reduced distal podomeres, some of which bear simple endites. This pattern is significantly different to that of Laminacaris chimera. The apparent presence of unpaired endites along the length of the appendage in Laminacaris, and the morphology of the endite on podomere 3 , with its blade-like elongated shape and perpendicular distally-directed auxiliary spines is however unique to Hurdiidae and consistently present in all members of the family (with the exception of the extremely derived giant filter feeder Aegirocassis).

The characters shared by the early Cambrian Laminacaris and Hurdiidae are noteworthy because most hurdiids derive from strata of Cambrian Series 3 or later, including the Stage 5 Burgess Shale and Stanley Glacier localities in Canada (Hurdia, Peytoia, Stanleycaris; Whittington \& Briggs 1985; Daley et al. 2009; 2013a; Daley \& Budd 2010; Caron et al. 2010), Stage 5 Spence Shale and Drumian Wheeler and Marjum Formations in Utah (Hurdia, Peytoia, Stanleycaris; Pates et al. 2017, 2018b), the early Ordovician Fezouata Formation (Aegirocassis and a Hurdia-like taxon; Van Roy \& Briggs 2011; Van Roy et al. 2015) and the Early Devonian Hunsrück Slate (Schinderhannes; Kühl et al. 2009). Indeed, in the Burgess Shale and Fezouata, hurdiids are the most abundant members of Radiodonta (Van Roy \& Briggs 2011; Daley et al. 2013a). Only three instances of older hurdiids are known - two being isolated frontal appendages and one an isolated carapace element. From Cambrian Series 2, Stage 3 of Poland, an appendage previously referred to as 'Cassubia' has been re-identified as a species of Peytoia (Daley \& Legg, 2015). The Balang Formation (Cambrian Series 2, Stage 4) in China has also revealed a single specimen of a frontal appendage similar to Peytoia nathorsti from the Burgess Shale (Liu 2013). The Shuijintuo Formation (Cambrian Series 2, Stage 4) in China is the source of a single specimen of Proboscicaris, later identified as a Hurdia P-element (Cui \& Huo, 1990; Daley et al. 2013a).

In contrast to its hurdiid-like characters, some other morphological features of Laminacaris are similar to members of Amplectobeluidae and Anomalocaridae. The elongated endite on podomere 3 in Laminacaris is situated on the first podomere of the distal articulated region of the appendage. An enlarged/elongated endite is present in the equivalent position (first podomere of the distal articulated region) in the amplectobeluid taxa Amplectobelua and Ramskoeldia (Cong et al. 2017, 2018).

However, Laminacaris bears unpaired auxiliary spines on this endite (and all other endites), while in Amplectobelua and Ramskoeldia the auxiliary spines on this endite are paired (Hou et al. 1995; Cong et al. 2017, 2018). If the endite on podomere 7 is in fact larger than on podomere 5 (three podomeres distal to the shaft), Laminacaris would bear additional similarities with Amplectobelua and Ramskoeldia, in which the endite on podomere 8 is larger than that on podomere 6 (also three podomeres distal to the shaft) (Cong et al. 2017, 2018). However, a trend of decreasing size of the endites of Laminacaris on even and odd podomeres cannot be confirmed with current evidence, while such a character is shared by the two genera of Amplectobeluidae (Cong et al. 2018). In addition, the podomere numbers in the shaft also differ between Laminacaris (two) and amplectobeluids (three) (although due to the often poorly preserved nature of the shaft this difference is tentative), and differences also exist in the dorsal spines between Laminacaris and amplectobeluids, with regards to both their numbers and size. These differences are inconsistent with Laminacaris as a member of Amplectobeluidae.

Lyrarapax, the inclusion of which in Amplectobeluidae remains uncertain (Cong et al. 2018), also bears an enlarged ventral endite with distally pointing auxiliary spines near its base (Cong et al. 
2014, 2016), resembling the very large endite of Laminacaris. However, in Lyrarapax the auxiliary spines of the enlarged endite increase in length from base to tip, and there are no auxiliary spines on the last third of the ventral endite (Cong et al. 2016 fig. 3), whereas in Laminacaris the auxiliary spines alternate as long and short and are present along the entire length of the ventral endite (Figs $1 \mathrm{H} ; 2 \mathrm{E}$ ). In addition, on the endites of other podomeres, Laminacaris bears distal-pointing auxiliary spines, while in Lyrarapax the auxiliary spines point proximally (L. unguispinus) or are totally absent (L. trilobus). Lyrarapax has fewer podomeres than Laminacaris.

Laminacaris also bears some similarity to some members of Anomalocaridae, such as Anomalocaris saron Hou et al., 1995, and Anomalocaris cf. canadensis, as well as A. briggsi (which did not ally with other species of Anomalocaris in recent phylogenetic analyses - see Vinther et al. 2014, Cong et al. 2014 and Van Roy et al. 2015). Indeed, the holotype of Laminacaris chimera had previously been identified as an affinis species of the Chengjiang taxon Anomalocaris saron (Hou et al. 2004), based on the fact that both A. saron (Fig. 2F, G) and Laminacaris have two podomeres in the shaft and 13 in the distal articulated region with an elongate and robust endite on the first podomere of the distal articulated region. However, the frontal appendage of Anomalocaris saron is generally more slender (Fig. 2F, G) than that of Laminacaris chimera (Figs 1A, B, E, F; 2A-D). Recently, two morphotypes were distinguished in the specimens previously assigned to Anomalocaris saron, with the one that differs from the holotype identified, together with partially articulated body parts, as Ramskoeldia consimilis (Cong et al. 2018). This restricts the frontal appendage morphology of Anomalocaris saron to the following set of character states: The shaft podomere 2 bears one tiny, simple spine-shaped endite; the endite on podomere 3 (the first podomere of the distal articulated region) is stouter than others, but with almost same length as, or even shorter than those of podomeres 4-11; auxiliary spines are only present on the proximal half of the ventral endites, with at least the two most tipwards being paired; the auxiliary spines are never perpendicular to the endites to which they attached; the dorsal spine on podomere 14 is large (probably longer than the length of the podomere) but the dorsal spines on podomeres 13(?) and 15 are quite small, with that on 15 also bearing a long terminal spine (Fig. 2F, G; see also Cong et al. 2018, fig 5c, f). This pattern of the endites and their attached auxiliary spines differs from Laminacaris chimera.

There are also numerous similarities between Laminacaris chimera and the Emu Bay Shale taxa Anomalocaris briggsi and Anomalocaris cf. canadensis (Daley et al. 2013b). A. briggsi bears an enlarged endite at the distal podomere of the shaft and first post-shaft podomere, and the remainder of the appendage bears ventral blades with distally and proximally pointing auxiliary spines, similar to Laminacaris. A. briggsi however has much longer ventral endites than Laminacaris, these being equal in length, paired, and not alternating as long and short, and they curve towards the base of the appendage rather than towards the distal end of the appendage (Daley et al. 2013a, fig. 1a,b) as seen in Laminacaris. Furthermore, the basal region of the ventral endites in A. briggsi is covered with numerous spinules, a feature entirely lacking in Laminacaris. A. cf. canadensis also has an enlarged endite on the distal shaft podomere (partially preserved) and a recurved enlarged endite on the first post-shaft podomere with five distally pointing auxiliary spines that increase in length from the base to the tip of the ventral endite (Daley et al. 2013a, fig. 4f-g), very similar to Laminacaris. The ventral endites along the rest of the appendage alternate long/short and again have a similar morphology to those of Laminacaris. The two taxa differ as the enlarged ventral endite in Anomalocaris cf. canadensis has more proximally pointing auxiliary spines, and its appendages also bear one more dorsal spine.

In summary, Laminacaris possesses a mosaic of characters from radiodont taxa of different families, which provides a basis for erecting this new genus and species.

\section{Discussion:}

\section{Frontal appendages and radiodont systematics}

As the most robust and commonly preserved part of the anatomy, frontal appendages provide key information for radiodont systematics. Features such as the presence of more than six podomeres separated by flexible arthrodial membranes, and at least one (and often two) rows of ventral endites 
allow isolated appendages, such as the ones described herein, to be identified as Radiodonta. Other body parts, including the radial mouthparts for which the Order Radiodonta was originally named, are not present or identifiable in all radiodonts (for example, in Lyrarapax).

Frontal appendages are also used in identifying animals to the family, genus, and species level. The variation in number of podomeres in the shaft and distal articulated region, morphology of ventral endites, presence and morphology of dorsal and terminal spines, and finer details such as auxiliary spines and podomere shape, are all employed to discriminate between taxa. At the species level, these differences are generally small, for example Ramskoeldia consimilis Cong et al., 2018 and R. platyacantha Cong et al., 2018 are distinguished based on the morphology of ventral endites. At the family level, however, these differences can be substantial, for example when comparing Hurdiidae, which have enlarged ventral endites exclusively on podomeres 2-6, with other radiodont families, which normally have ventral endites on more than five successive podomeres. In other cases, the differences between frontal appendages of different families can be more subtle, as seen for some members of Anomalocarididae and Amplectobeluidae. While the type species Anomalocaris canadensis and Amplectobelua symbrachiata have frontal appendages that differ substantially in terms of the numbers of podomeres, morphology of the ventral endites, and robustness of proximal ventral endite and distal dorsal spines, the frontal appendage of the recently described amplectobeluid genus Ramskoeldia is more subtly different from that of Anomalocaris. Ramskoeldia and Anomalocaris appendages have the same number of podomeres in the distal articulated region, and differences are limited to Ramskoeldia having a longer ventral spine on podomere 8 than on podomere 6, which is not seen in Anomalocaris. The major difference between these two taxa is that Ramskoeldia has gnathobase-like structures similar to those seen in Amplectobelua and mouthparts made up of smooth and tuberculate plates (Cong et al. 2018) whereas Anomalocaris canadensis has a triradial oral cone and no gnathobase-like structures have been recognized (Daley \& Bergström 2012; Daley \& Edgecombe 2014). Indeed, frontal appendages alone can sometimes not be enough to distinguish between taxa at the species level, as seen for Hurdia victoria and H. triangulata, which have indistinguishable frontal appendages but greatly differing frontal carapace elements (Daley et al. 2013a). This variability in the usefulness of frontal appendages for deciphering radiodont systematics means that identifying new taxa known only from frontal appendages can be challenging, particularly when features of numerous families are present, as seen in Laminacaris chimera.

The presence of the features of a number of families raises the possibility that Laminacaris chimera could in fact be stemward of the taxa discussed above, rather than a derived member of one of the families with some convergent frontal appendage characters. Cucumericrus decorata, a contemporaneous fossil from Chengjiang, is arguably the most stemward radiodont, as it bears lobopodous walking legs alongside swimming flaps typical of radiodonts (Hou et al. 1995). This raises the possibility that the appendages described herein might belong to a radiodont closely related to Cucumericrus, and therefore represent a frontal appendage morphology predating the split between hurdiids and anomalocaridids/amplectobeluids.

\section{Ecological interpretation}

The frontal appendages of Radiodonta were undoubtedly used in feeding, and a variety of feeding modes have been reconstructed for the group based on functional morphology. These can be broadly grouped into three categories: active raptorial predators with the ability to manipulate individual prey items (e.g. Anomalocaris canadensis, Amplectobelua symbrachiata); generalist predators that sifted through sediment and/or swept their appendages through the water column to trap prey items, often in conjunction with an enlarged frontal carapace to limit prey movement (e.g. Hurdia victoria, Peytoia nathorsti); and suspension feeding taxa that used numerous fine spines to filter particles and plankton from the water column (e.g. Aegirocassis benmoulai, Tamisiocaris borealis) (Daley \& Budd 2010; Vinther et al. 2014; Van Roy et al. 2015). The first two feeding modes largely correspond to the different families recovered in phylogenetic analyses, with Anomalocarididae and Amplectobeluidae being interpreted as active raptorial predators and Hurdiidae being interpreted as sediment sifting or suspension feeding predators. However, the suspension feeding mode of life seems to have arisen in at least two separate lineages in Radiodonta, once with Tamisiocaris and again with Aegirocassis. 
Anomalocarididae and Amplectobeluidae use different strategies to grasp prey items. For example, Amplectobelua symbrachiata presumably trapped prey items between its enlarged proximal endite and the strong simple spines on more distal podomeres (Cong et al. 2017), while Anomalocaris canadensis used its flexible appendage to actively grab prey (Briggs 1979; Whittington \& Briggs 1985; Daley \& Edgecombe 2014). Caryosyntrips is inferred to have used its paired appendages in conjunction to slice at prey (Daley \& Budd, 2010, Pates \& Daley 2017). The morphology of the new taxon described here, Laminacaris chimera, suggests that it was also an active raptorial predator, combining the feeding modes of both Anomalocaris and Amplectobelua. The presence of a robust ventral endite and a claw-like distal end of the appendage with robust dorsal spines suggests that this animal used its frontal appendages in a similar way to Amplectobelua, holding its prey tightly between the enlarged proximal endite and more distal podomeres. The presence of prominent triangular flexible cuticle between podomeres, and alternating large and small ventral endites with distallypointing auxiliary spines would have imparted greater flexibility than is inferred for Amplectobelua, and in this way the feeding mode of Laminacaris resembles that of Anomalocaris. In Laminacaris, the arrangement of auxiliary spines would have created a sharp surface along the length of the appendage against which to slice prey. As a result this taxon is interpreted as combining the power of the Amplectobelua feeding mode with the flexibility of Anomalocaris. If Laminacaris depicts the morphology of radiodont frontal appendages near the split between families, it would suggest a basal feeding strategy for the group as active raptorial predators, with suspension feeding and sediment sifting representing derived feeding modes.

\section{Conclusion}

Recent collecting efforts have led to the discovery and description of numerous new radiodont taxa, and the ever-increasing diversity of the group has revealed entirely new arrangements of both the body, for example the paired body flaps of Aegirocassis and other hurdiids (Van Roy et al. 2015), and the head, as seen in the recent discovery of highly variable (or absent) oral cones (Cong et al. 2014, 2016) and the presence of gnathobase-like structures (Cong et al. 2017, 2018). Diversity in cephalic structures is perhaps most apparent when examining the frontal appendages, which have a highly variable morphology, presumably as a result of evolutionary selection pressure related to their ecology and feeding mode of life. Isolated frontal appendages like Laminacaris are sometimes difficult to assign to a particular radiodont family, as indeed is the case for some other radiodonts known only from frontal appendages (e.g., Caryosyntrips) or from other body parts (e.g., Cucumericrus and Lyrarapax). Despite this difficulty, recent descriptive work on new species, as conducted here, and revisions of the morphology of several previously described taxa (e.g., Daley et al. 2013; Daley \& Edgecombe 2014; Cong et al. 2017) have clarified the anatomy of enigmatic structures (Daley et al. 2009; Daley \& Bergström 2012; ) and revealed the importance of Radiodonta for understanding the early evolution of arthropods (Daley et al. 2009; Cong et al. 2014, 2018; Van Roy et al. 2015). The mosaic of characters seen in Laminacaris lends further evidence to the overall interpretation of Radiodonta as highly diverse, even during the earliest known stages of the group's evolution during Cambrian Series 2.

Acknowledgements. This work was supported by National Science Foundation of China grants 41572015 and U1302232 and Leverhulme Trust Research Project Grant RPG-2015-441. S. Pates was supported by funding from an Oxford-St Catherine's Brade-Natural Motion Scholarship. We thank Mr. Yang Zhao for his help in preparing and photographing the holotype.

\section{DATA ARCHIVING STATEMENT}

This published work and the nomenclatural acts it contains, have been registered in ZooBank: http://zoobank.org/References/XXXXXXXXX 


\section{References:}

BRIGGS, D. E. G. 1979. Anomalocaris, the largest known Cambrian arthropod. Palaeontology, 22, 631-664.

CARON, J.B., GAINES, R.R., MÁNGANO, M.G., STRENG, M., and DALEY, A.C. 2010. A new Burgess Shale-type assemblage from the "thin" Stephen Formation of the southern Canadian Rockies. Geology, 38, 811-814.

COLLINS, D. 1996. The "evolution" of Anomalocaris and its classification in the arthropod class Dinocarida (nov.) and order Radiodonta (nov.). Journal of Paleontology, 70, 280-293.

CONG, P., MA, X., HOU, X., EDGECOMBE, G. D. and STRAUSFELD, N. J. 2014. Brain structure resolves the segmental affinity of anomalocaridid appendages. Nature, 513, 538-542.

--- DALEY, A.C., EDGECOMBE, G.D., HOU, X., and CHEN, A., 2016. Morphology of the radiodontan Lyrarapax from the early Cambrian Chengjiang biota. Journal of Paleontology, 90, $663-671$.

--- --- --- --- 2017. The functional head of the Cambrian radiodontan (stem-group Euarthropoda) Amplectobelua symbrachiata. BMC Evolutionary Biology, 17, 208.

--- EDGECOMBE, G.D., DALEY, A.C., GUO, J., PATES, S. and HOU, X.G. 2018. New radiodontans with gnathobase-like structures from the Cambrian Chengjiang Biota and implications for the systematics of Radiodonta. Papers in Palaeontology, in press.

CUI, Z.L. and HUO, S. C. 1990. New discoveries of Lower Cambrian crustacean fossils from Western Hubei. Acta Palaeontologica Sinica, 29, 321-330.

DALEY, A. C., and BERGSTRÖM, J. 2012. The oral cone of Anomalocaris is not a classic “Peytoia". Naturwissenschaften, 99, 501-504.

--- and BUDD, G. E. 2010. New anomalocaridid appendages from the Burgess Shale, Canada. Palaeontology, 53, 721-738.

--- and LEGG, D. A. 2015. A morphological and taxonomic appraisal of the oldest anomalocaridid from the Lower Cambrian of Poland. Geological Magazine, 152, 949-955.

--- and PEEL, J. S. 2010. A possible anomalocaridid from the Cambrian Sirius Passet lagerstätte, North Greenland. Journal of Paleontology, 84, 352-355.

--- BUDD, G.E., CARON, J.B., EDGECOMBE, G. D. and COLLINS, D. 2009. The Burgess Shale anomalocaridid Hurdia and its significance for early euarthropod evolution. Science, 323, $1597-1600$.

--- --- -- 2013a. Morphology and systematics of the anomalocaridid arthropod Hurdia from the Middle Cambrian of British Columbia and Utah. Journal of Systematic Palaeontology, 11, 743-787.

--- and EDGECOMBE, G. D. 2014. Morphology of Anomalocaris canadensis from the Burgess Shale. Journal of Paleontology, 88, 68-91.

--- PATERSON, J. R., EDGECOMBE, G. D., GARCÍA-BELLIDO, D. C. and JAGO, J. B. 2013b. New anatomical information on Anomalocaris from the Cambrian Emu Bay Shale of South Australia and a reassessment of its inferred predatory habits. Palaeontology, 56, 971-990.

HOU, X.G., SIVETER, D.J., SIVETER, D.J., ALDRIDGE, R.J., CONG, P., GABBOTT, S.E., MA, X., PURNELL, M.A. and WILLIAMS, M. 2017. The Cambrian fossils of Chengjiang, China: the flowering of early animal life. $2^{\text {nd }}$ ed. John Wiley \& Sons.

--- ALDRIDGE, R.J., BERGSTRÖM, J., SIVETER, D.J., SIVETER, D.J. and FENG, X.H. 2004. The Cambrian fossils of Chengjiang, China: the flowering of early animal life. $1^{\text {st }} \mathrm{ed}$. BlackWell.

--- BERGSTRÖM, J. and AHLBERG, P. 1995. Anomalocaris and other large animals in the Lower Cambrian Chengjiang fauna of southwest China. GFF, 117, 163-183.

KÜHL, G., BRIGGS, D.E. and RUST, J. 2009. A great-appendage arthropod with a radial mouth from the Lower Devonian Hunsrück Slate, Germany. Science, 323 771-773.

LANKESTER, E.R. 1904. The structure and classification of Arthropoda. Quarterly Journal of Microscopical Science, 47, 523-582.

LENDZION, K. 1975. Fauna of the Mobergella Zone in the Polish Lower Cambrian. Kwartalnik geologiczny 19, 237-242.

LIU, Q. 2013. The first discovery of anomalocaridid appendages from the Balang Formation (Cambrian Series 2) in Hunan, China: Alcheringa, 37, 1-6. 
NEDIN, C. 1995. The Emu Bay Shale, a Lower Cambrian fossil Lagerstätten, Kangaroo Island. Memoirs of the Association of Australasian Palaeontologists, 18, 133-141.

PATES, S. and DALEY, A.C. 2017. Caryosyntrips: a radiodontan from the Cambrian of Spain, USA and Canada. Papers in Palaeontology, 3, 461- 470.

--- --- and ORTEGA-HERNÁNDEZ, J. 2017. Aysheaia prolata from the Wheeler Formation

(Drumian, Cambrian) is a frontal appendage of the radiodontan Stanleycaris. Acta Palaeontologica Polonica, 62, 619-625.

--- --- and --- 2018a. Response to comment "Aysheaia prolata from the Wheeler Formation

(Drumian, Cambrian) is a frontal appendage of the radiodontan Stanleycaris" with the formal description of Stanleycaris. Acta Palaeontologica Polonica. 63, 105-110.

--- --- and LIEBERMAN, B.S. 2018b. Hurdiid radiodontans from the middle Cambrian (Series 3) of Utah. Journal of Paleontology, 92, 99-113.

RAYMOND, P.E. 1935. Leanchoilia and other mid-Cambrian Arthropoda. Bulletin of the museum of comparative zoology at Harvard College, 76, 205-230.

RESSER, C.E. 1929. New lower and middle Cambrian Crustacea. Proceedings of the United States National Museum, 76, 1-18.

VAN ROY, P., and BRIGGS, D.E.G. 2011. A giant Ordovician anomalocaridid. Nature, 473, 510-513.

--- DALEY, A. C. and BRIGGS, D. E. G. 2015. Anomalocaridid trunk limb homology revealed by a giant filter-feeder with paired flaps. Nature, 522, 77-80.

VINTHER, J., STEIN, M., LONGRICH, N. R., and HARPER, D. A. 2014. A suspensionfeeding anomalocarid from the Early Cambrian. Nature, 507, 496-499.

WALCOTT, C.D. 1911. Cambrian geology and paleontology. II. Middle Cambrian holothurians and medusae. Smithsonian Miscellaneous Collections, 57, 41-68.

--- 1912. Middle Cambrian Branchiopoda, Malacostraca, Trilobita and Merostomata. Smithsonian Miscellaneous Collections, 57, 145-228.

WHITEAVES, J.F. 1892. Description of a new genus and species of phyllocarid crustacean from the Middle Cambrian of Mount Stephen, British Columbia. Canadian Record of Science, 5, 205-208.

WHITTINGTON, H. B., and BRIGGS, D. E. 1985. The largest Cambrian animal, Anomalocaris, Burgess Shale, British Columbia. Philosophical Transactions of the Royal Society of London. Series B, Biological Sciences, 309, 569-609.

ZENG, H., ZHAO, F., YIN, Z. and ZHU, M. 2018. Morphology of diverse radiodontan head sclerites from the early Cambrian Chengjiang Lagerstatte, south-west China. Journal of Systematic Palaeontology, 16, 1-37. 


\section{Figure}
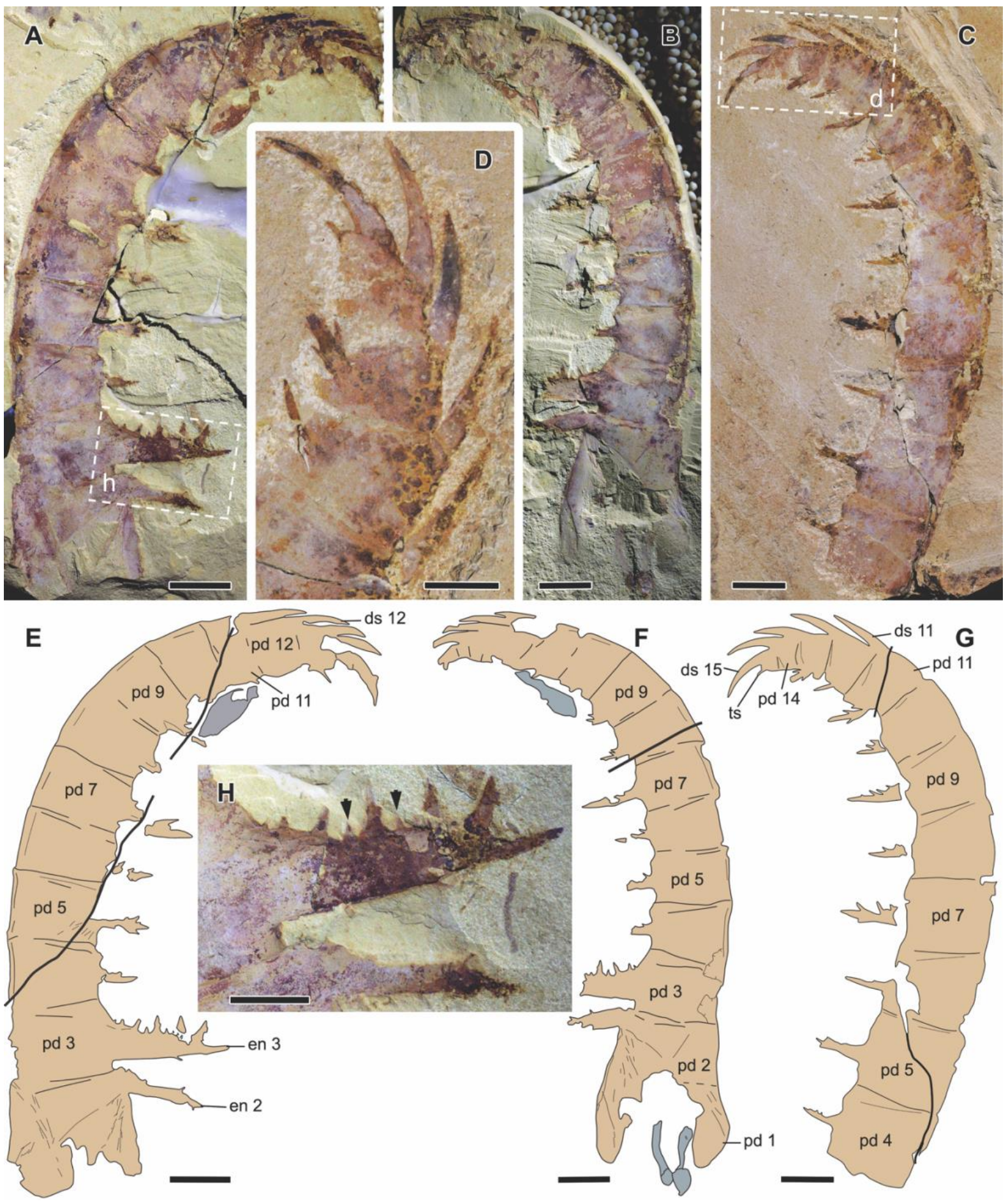

FIG. 1. Laminacaris chimera gen. et sp. nov. from the Chengjiang biota. A, B, holotype, RCCBYU 10251, part (A) and counterpart (B), showing nearly complete frontal appendages. C, paratype, frontal appendage, YKLP 13338, showing the distal podomeres with distinctive endites and dorsal spines. D, close-up of the distal podomeres with dorsal spines in the paratype (boxed in C). E, F, interpretative drawings of the part and counterpart of the holotype. G, interpretative drawings of the paratype. $\mathrm{H}$, close-up of the endites on podomeres 2 and 3 (boxed in A). Abbreviations: ds, dorsal spine of frontal appendage; en, endite on ventral side of podomeres; pd, podomere; ts, terminal spine. Scale bars, A, B, D-F, $10 \mathrm{~mm}$; C, G, $20 \mathrm{~mm}$; H, $5 \mathrm{~mm}$. 

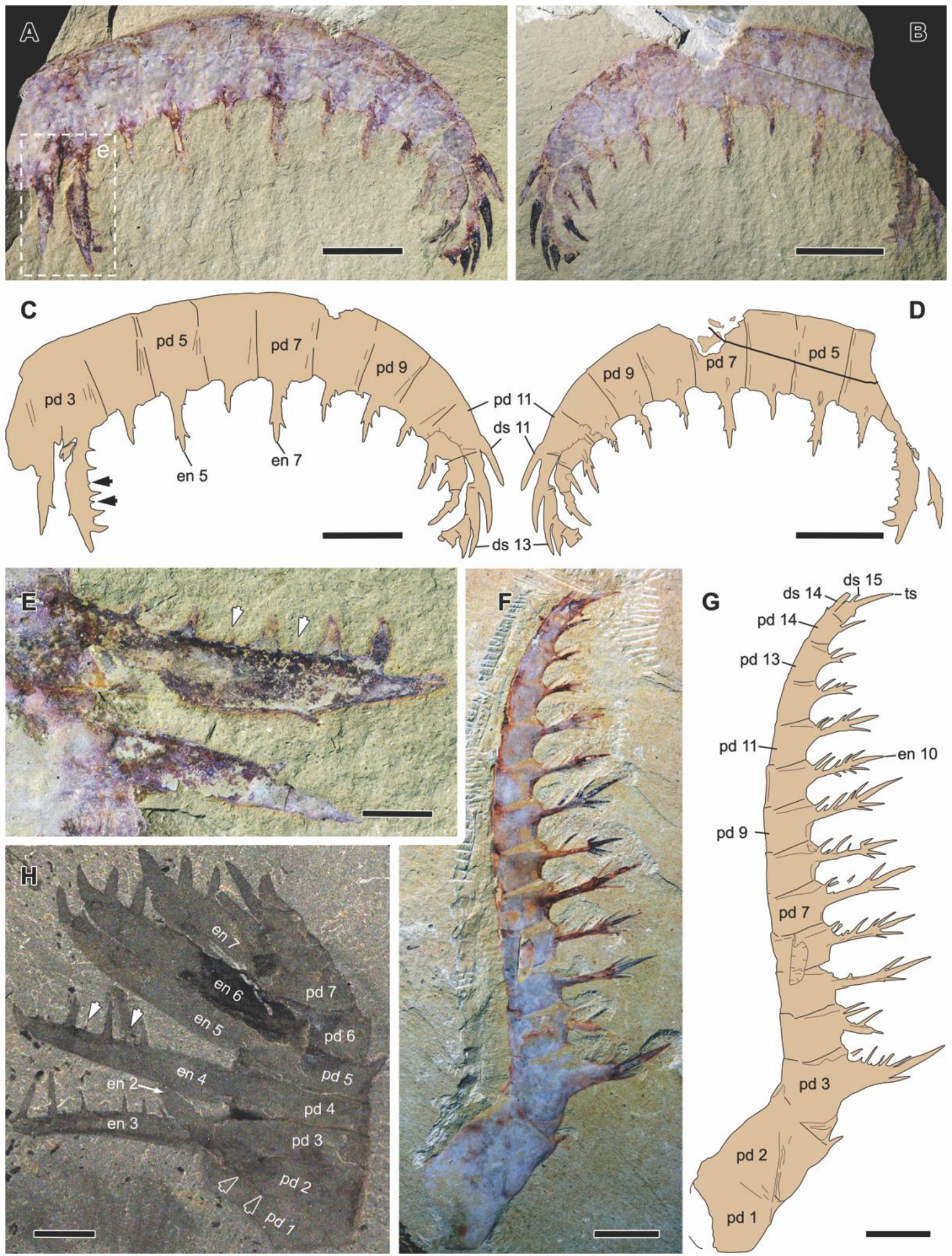

FIG. 2. Comparison on the elongated endites of Laminacaris chimera. A, B, part and counterpart of a nearly complete frontal appendage of $L$. chimera, CJHMD 00003. C, D, interpretative drawings of A and $\mathrm{B}$ respectively, black arrows in $\mathrm{C}$ indicating the short auxiliary spines between the longer ones. $\mathrm{E}$, close-up of the endites on podomere 2 and 3 (boxed in A), white arrows indicating the short auxiliary spines between the longer ones. F, frontal appendage of Anomalocaris saron, YKLP 13459. G, interpretative drawing of F. H, complete frontal appendage of Hurdia victoria (ROM 60048); white arrows indicating the short auxiliary spines between the longer ones; hollow arrows indicating the 
weak boundary between podomeres 1 and 2; note endite 2 extending beneath endite 3 . Abbreviations: ds, dorsal spine of frontal appendage; en, endite on ventral side of podomeres; pd, podomere; ts, terminal spine. Scale bars, A-D, 20 mm; E, H, 5 mm; F, G, 10 mm.

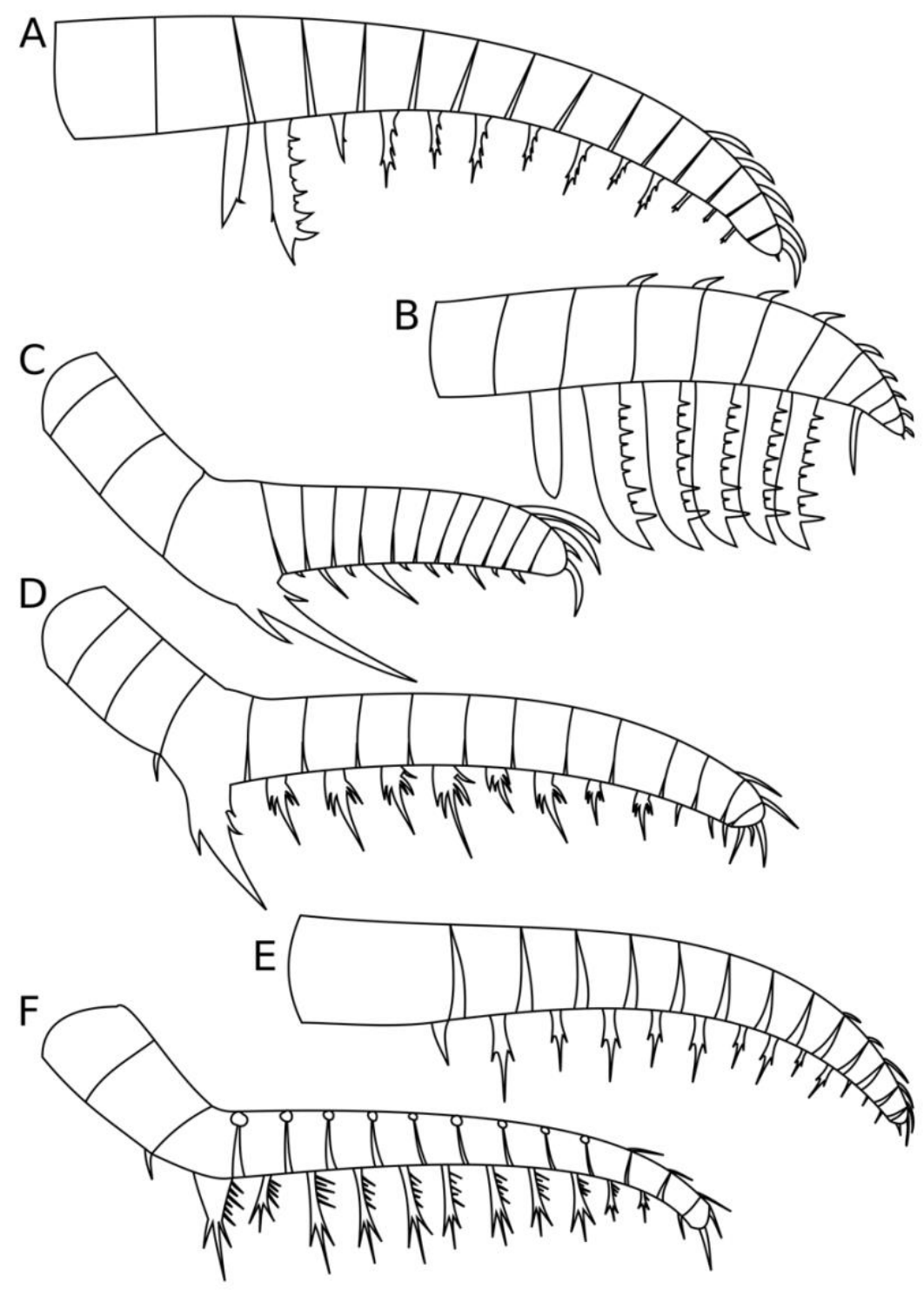

FIG. 3. Comparative sketches of radiodont frontal appendages. A, Laminacaris chimera gen. et sp. nov.. B, Hurdia victoria Walcott 1912. C, Amplectobelua symbrachiata Hou et al. 1995. D, Ramskoeldia consimilis Cong et al. 2018. E, Anomalocaris canadensis Whiteaves 1892. F, Anomalocaris saron Hou et al. 1995. 
Table

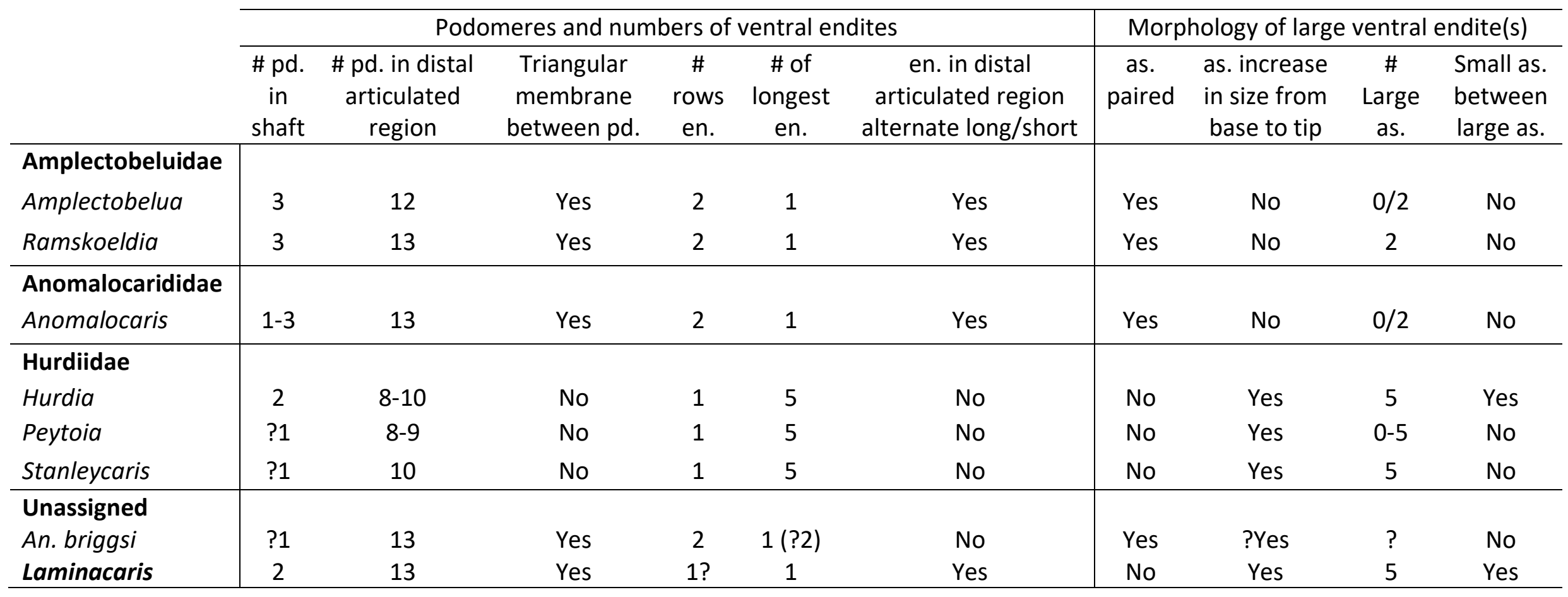

Table 1. Frontal appendage characters that distinguish radiodont genera. Abbreviations: as, auxiliary spine; en, ventral endite; pd, podomere. 